\title{
Background Studies to Tackle Environmental Problems: On Solar Projects in Portugal
}

\author{
Nuno Domingues* \\ Instituto Superior de Engenharia de Lisboa-ADEM, Lisbon, Europe
}

*Corresponding author: Nuno Domingues, Instituto Superior de Engenharia de Lisboa-ADEM, Rua Conselheiro Emídio Navarro, 1, 1959-007 Lisbon, Portugal

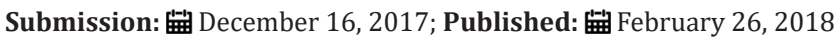

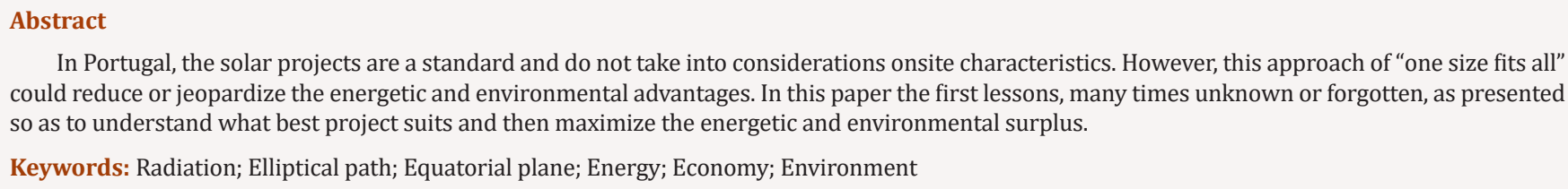

In Portugal, the solar projects are a standard and do not take into considerations onsite characteristics. However, this approach of "one size fits all" could reduce or jeopardize the energetic and environmental advantages. In this paper the first lessons, many times unknown or forgotten, as presented so as to understand what best project suits and then maximize the energetic and environmental surplus.

Keywords: Radiation; Elliptical path; Equatorial plane; Energy; Economy; Environment

\section{Introduction}

The power of the Sun is $3.826 \times 10^{26} \mathrm{~W}$. The Sun produces its energy through nuclear fusion, where 4 million tons of hydrogen per second is converted into helium.

The energy radiated by the Sun that comes to the Earth is given by the following equation:

$\mathrm{E}=\mathrm{h} . \mathrm{v}=4.1026 \mathrm{~J}$

Where h is Planck's constant (has the value $6.626 .10^{-34} \mathrm{Js}$ ) and $v$ is the speed of light in vacuum (has the value 299792 458m/s). The amount of solar energy that reaches, per unit time and per unit area, the surface perpendicular to the Sun's rays, it is called radiation intensity. The radiation intensity, also called solar constant, is given by:

$$
I=\frac{P}{S}=1353 \mathrm{~W} / \mathrm{m}^{2}
$$

Where,

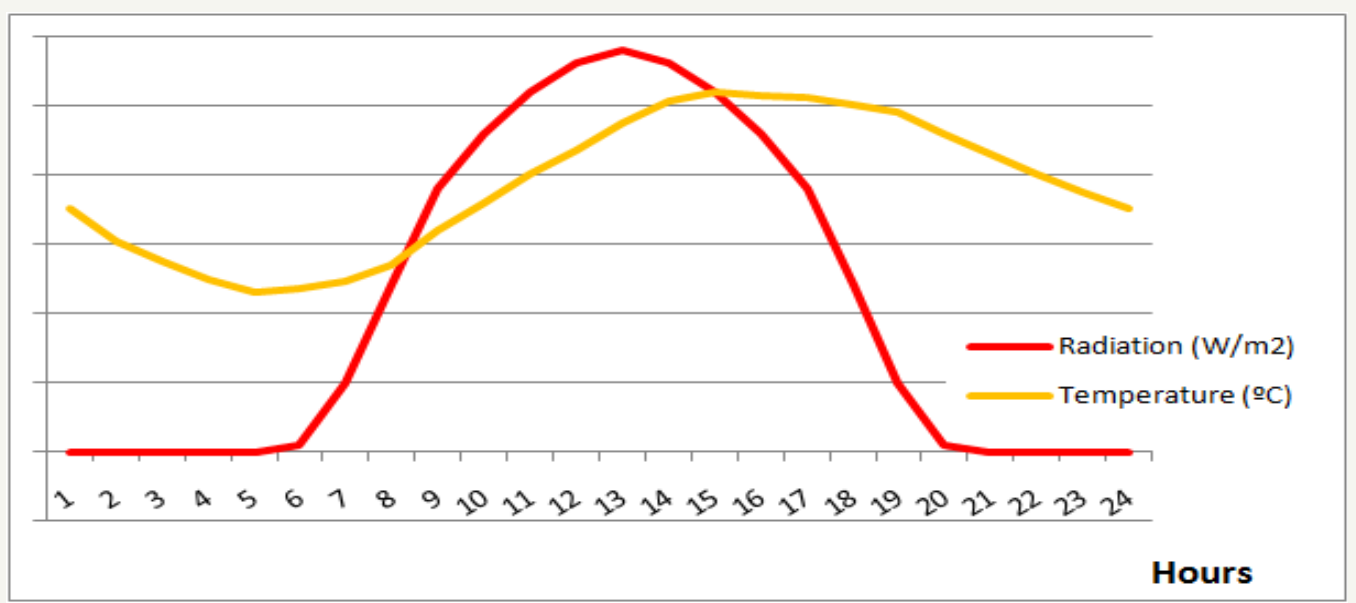

Figure 1: Typical curve of diary solar cycle.

The intensity of the radiation depends on the angle of the incidence of the Sun's rays and the trajectory of the Sun. The trajectory of the Sun varies throughout the day and throughout the year. (Figure $1 \& 2$ ) illustrate the typical curve of solar radiation and temperature northern of the Equator. The values are not presented because the goal is to only show the form evolution. The global radiation that reaches a plan located on the Earth's surface can be decomposed into three components 


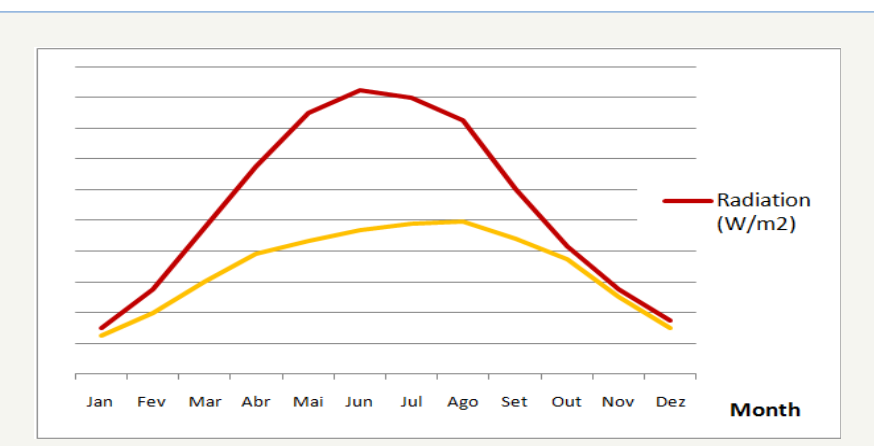

Figure 2: Typical curve of annual solar cycle.

\section{Direct radiation}

Which corresponds to the energy received from the Sun (about $70 \%$ of the total radiation),

\section{Diffuse radiation}

Which corresponds to the energy spread by the atmosphere, dust in suspension and the clouds (about 28\% of the total radiation),

\section{Radiation reflected}

The portion of the radiation that is reflected upon reaching the ground, called albedo, i.e. radiation, is the radiation that reaches a surface to be reflected by other surface (about 2\% of the total radiation).

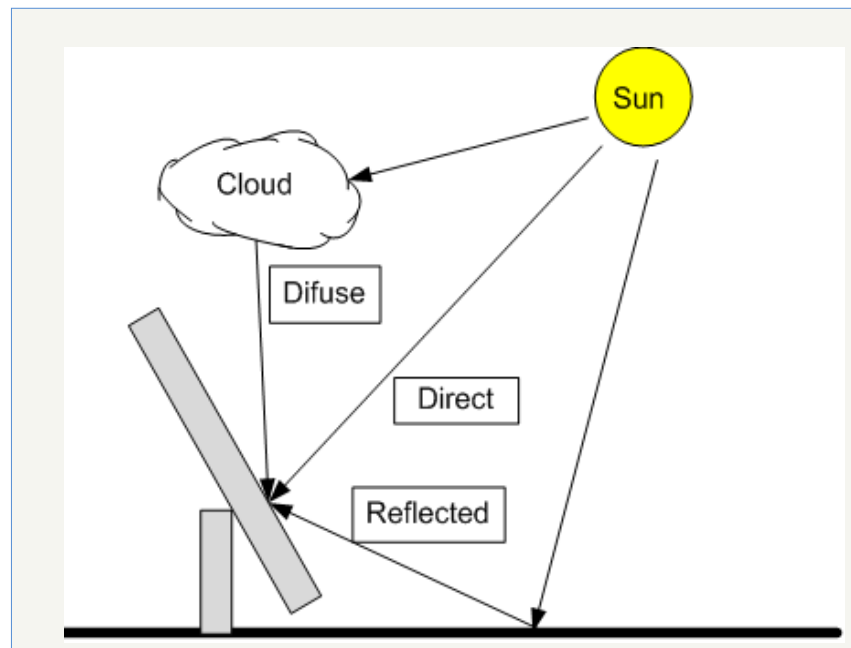

Figure 3: Decomposition of solar radiation.

The total radiation that comes to a point on the Earth is the sum of these 3 components. (Figure 3) illustrates how the solar radiation reaches a point above the Earth ground (e.g., the solar panel). (Figure $4 \& 5$ ) illustrate the division of radiations in their components, for the curves in (Figure $1 \& 2$ ) respectively. As before, these Figures are not the values because it only wants to show the form of evolution. (Figure 6) illustrates the typical pattern of direct and diffuse radiation from daily total in Lisbon [1]. The Earth makes its movement around the Sun in an elliptical path with then inclination of approximately $23.5^{\circ}$ relative to the equatorial plane. This causes the change of elevation of the Sun on the horizon throughout the day, which leads to the different seasons of the year. The succession of the seasons causes the annual variation of temperatures, due to the amount of energy that comes to the Earth. It is curious to note that in Portugal the hottest days are when the Earth is farthest from the Sun. The (Figure 7) illustrates the average annual radiation in January and in July for Continental Portugal for the year 2016 [2].

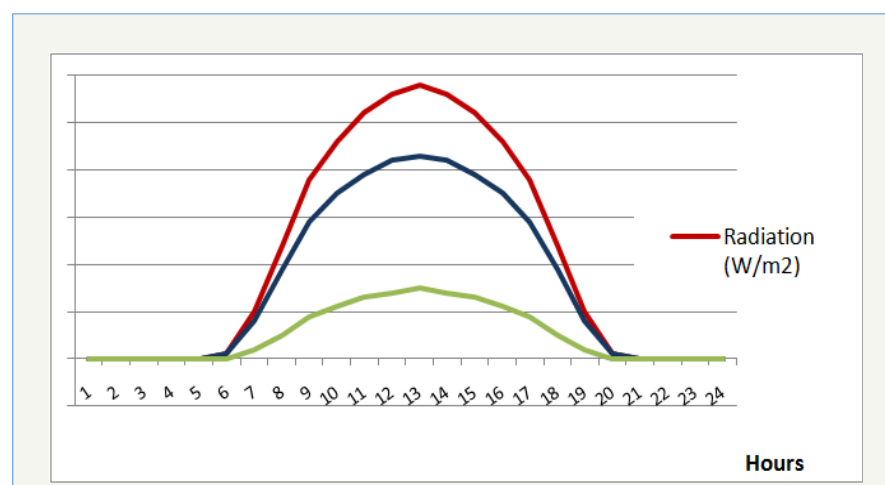

Figure 4: Radiation components in a typical daily cycle of solar energy.

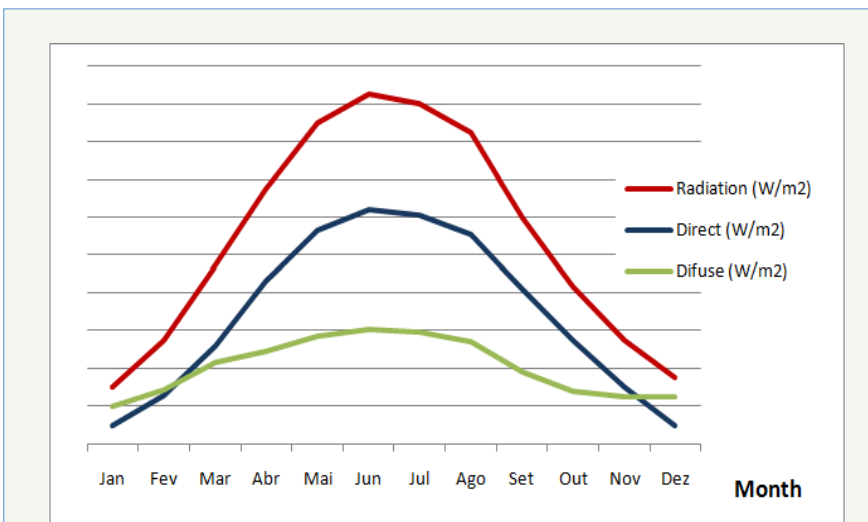

Figure 5: Radiation components in a typical annual cycle of solar energy.

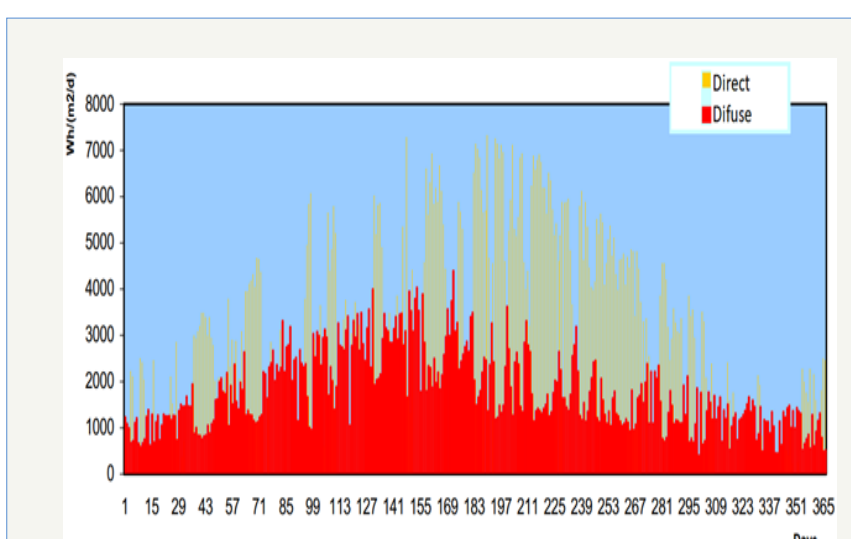

Figure 6: Typical direct and diffuse radiation daily total in Lisbon.

When doing the economic viability of solar energy projects it is important to know the radiation on site. Thus, it is important to analyze the historic data but also to estimate the future values. The first method to calculate the monthly average daily 
radiation was developed in 1962 [3] and was improved in 1977 [4]. Another important factor is the orientation of the solar panel. In the same location, the amount of energy produced and one's distribution throughout the day depends on the orientation of the solar panel. Until recently, the solar installation projects teams decided that the panels should all be facing south in order to maximize the production. However, this orientation is inappropriate considering reality and lack of solar production in times of consumption and existing production peaks. The Southfacing panels absorb most of the energy in the morning and at noon. The period in which there is a greater demand for energy is aggravated in the afternoons mainly in hot summer afternoons.
If solar panels are facing West to your electricity generation will match consumption. The reason of the photovoltaic solar panels (to produce electricity) are all oriented to the South was for the project have more economic than energy focus: owners of solar panels were paid by amount of electricity produced, having soon all incentive to maximize this energy production, even if it is not aligned with the consumption in the power grid. The projects of solar thermal panels (water heating) follow the guidance of photovoltaic solar projects. Another important factor that has not been taken into account in the projects of photovoltaic solar panels was is that the incoming variation of temperature and the estimated production values have not been corrected.
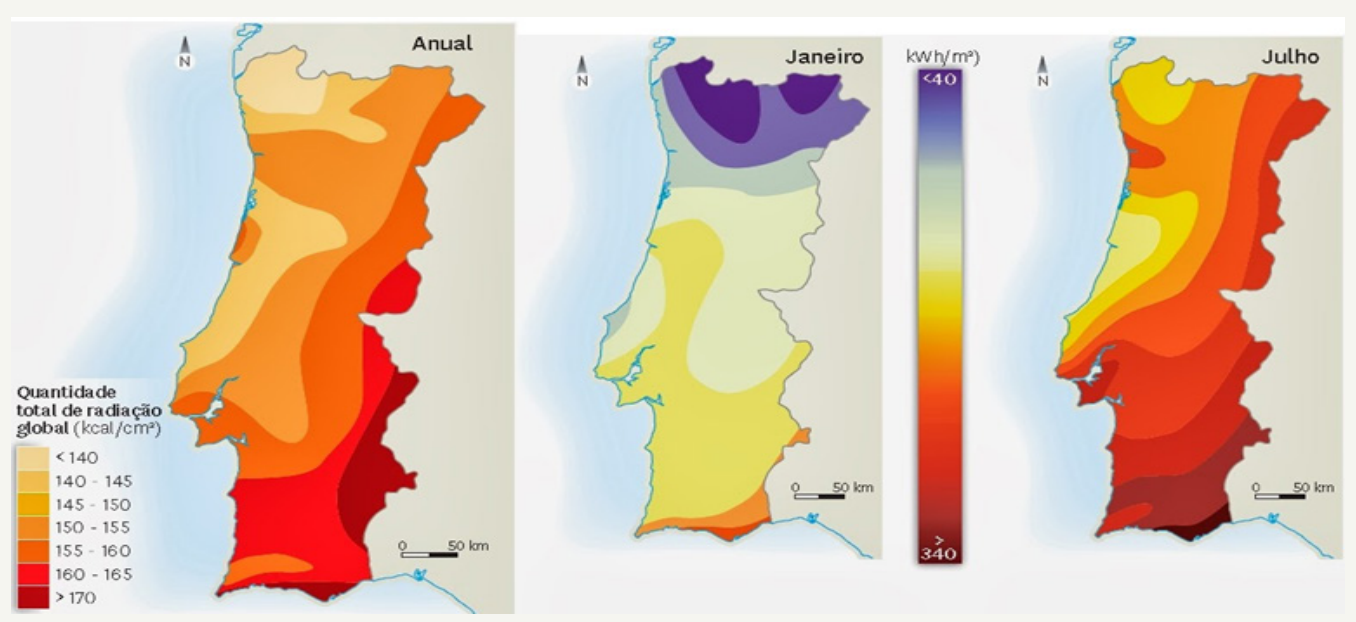

Figure 7: Annual global radiation distribution and annual average in Portugal mainland.

\section{Conclusion}

To maximize the solar project there are some onsite characteristics that have huge importance for the project viability in the three vectors: energy, economy and environment. The global study should be complemented with onsite study to maximize the surplus of all vectors.

\section{References}

1. Photovoltaics-Manual on technologies, design and installation; Energia
Fotovoltaica-Manual e Guia Técnico sobre tecnologias, projeto e instalação; European project.

2. Digital atlas of environment, APA-Portuguese environment agency, Portugal.

3. Liu B, Jordan R (1962) Daily insolation on tilted surfaces toward the equator. Ashrae Journal, pp. 54.

4. Klein SA (1997) Calculation of monthly average insolation on tilted surfaces. Solar Energy, pp. 325-329.

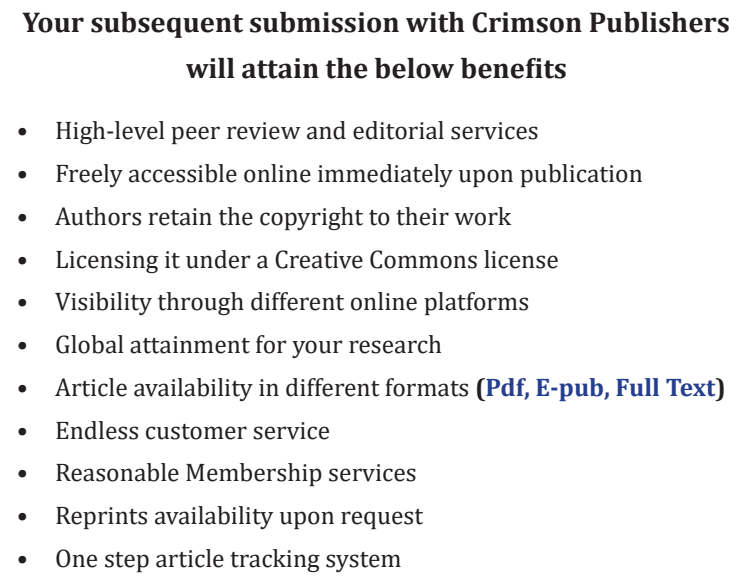

- High-level peer review and editorial services

- Freely accessible online immediately upon publication

- Authors retain the copyright to their work

- Licensing it under a Creative Commons license

- Visibility through different online platforms

- Global attainment for your research

- Article availability in different formats (Pdf, E-pub, Full Text)

- Endless customer service

- Reasonable Membership services

- Reprints availability upon request

- One step article tracking system 